\title{
Darmstadtium, Roentgenium and Copernicium Form Strong Bonds With Cyanide
}

\author{
Taye B. Demissie*and Kenneth Ruud ${ }^{\dagger}$
}

March 23, 2017

\begin{abstract}
We report the structures and properties of the cyanide complexes of three superheavy elements (darmstadtium, roentgenium and copernicium) studied using two- and four-component relativistic methodologies. The electronic and structural properties of these complexes are compared to the corresponding complexes of platinum, gold and mercury. The results indicate that these superheavy elements form strong bonds with cyanide. Moreover, the calculated absorption spectra of these superheavy-element cyanides show similar trends to those of the corresponding heavy-atom cyanides. The calculated vibrational frequencies of the heavy-metal cyanides are in good agreement with available experimental results lending support to the quality of our calculated vibrational frequencies for the superheavy-atom cyanides.
\end{abstract}

\footnotetext{
${ }^{*}$ Centre for Theoretical and Computational Chemistry, Department of Chemistry, UiT The Arctic University of Norway, N-9037 Tromsø, Norway

${ }^{\dagger}$ Centre for Theoretical and Computational Chemistry, Department of Chemistry, UiT The Arctic University of Norway, N-9037 Troms $\varnothing$, Norway
} 


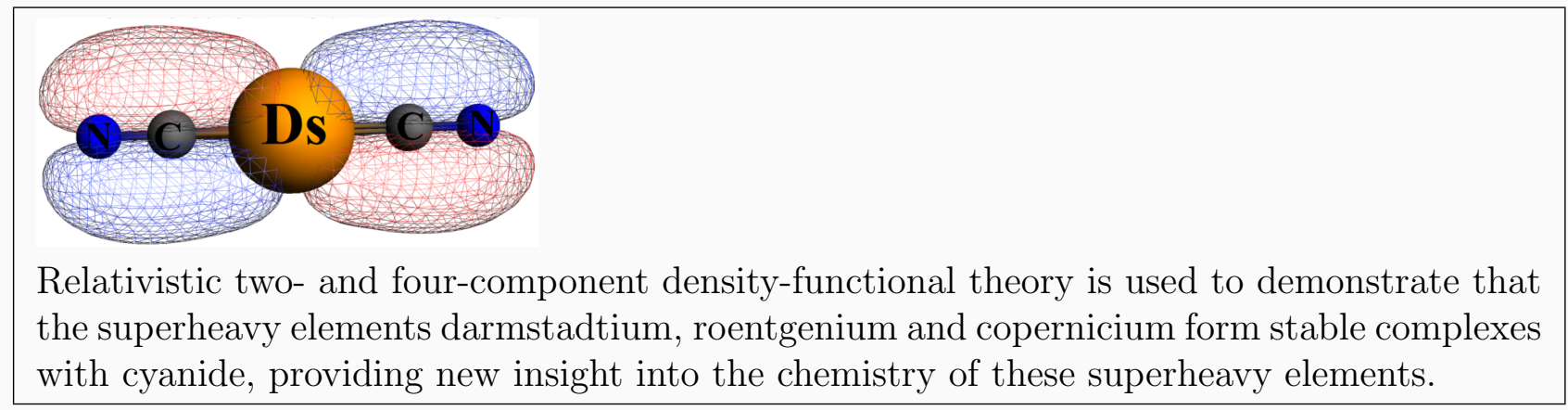




\section{INTRODUCTION}

The term heavy atom refers roughly to elements in the $4^{\text {th }}-6^{\text {th }}$ periods of the periodic table, whereas elements in the $7^{\text {th }}$ period are called superheavy elements. Heavy-element compounds have been rather extensively studied ${ }^{1-7}$ compared to the superheavy ones. This is due to the abundance of the heavy elements and the many uses of heavy-element compounds; for instance, gold dicyanide $\left(\mathrm{Au}(\mathrm{CN})_{2}^{-}\right)$was used in gold mining, ${ }^{8,9}$ platinum cyanides are used in nanomaterials, ${ }^{10}$ whereas mercury(II) cyanide $\left(\mathrm{Hg}(\mathrm{CN})_{2}\right)$ was used as an antiseptic ${ }^{11}$ until this was stopped due to its toxicity. ${ }^{12}$ In contrast, the lack of a natural abundance of the super-heavy elements has limited the number of studies of compounds involving these super-heavy elements. In particular, with the exception of $\mathrm{RgCN},{ }^{6}$ there has been no studies of the cyanide complexes of Ds, Rg and Cn reported previously in the literature. Patzschke and Pyykkö ${ }^{13}$ studied the properties of darmstadtium carbonyl and carbide and compared them to platinum carbide and carbonyl and found that darmstadtium resembled platinum in its bonding properties. ${ }^{13}$ Theoretical studies of darmstadtium hexafluoride $\left(\mathrm{DsF}_{6}\right)$ and darmstadtium tetrachloride $\left(\mathrm{DsCl}_{4}\right)$ have also been reported and have been shown to have properties similar to those of the lighter group analogues. ${ }^{14-16}$

The structure and bonding properties of roentgenium monocyanide have been compared with the cyanides of copper, silver and gold. ${ }^{6}$ Theoretical studies on the electronic structures of $\operatorname{RgX}(\mathrm{X}=\mathrm{H}, \mathrm{F}, \mathrm{Cl}, \mathrm{Br}, \mathrm{O}, \mathrm{Au}$, or $\mathrm{Rg})$ have also been reported ${ }^{5}$ where the $\mathrm{Rg}-\mathrm{H}$ bond in $\mathrm{RgH}$ was found to be strong due to relativistic effects, $153.0 \mathrm{pm}$ using ZORA and $150.3 \mathrm{pm}$ using spin-orbit pseudopotential coupled cluster calculations, in contrast to $190.8 \mathrm{pm}$ using nonrelativistic calculations (a 27\% relativistic bond-length contraction). Calculations using two-component spin-orbit-coupled relativistic energy-adjusted pseudopotentials showed that the $\mathrm{Cn}-\mathrm{H}$ bond length in $\mathrm{CnH}^{+}$is shorter than the $\mathrm{Zn}-\mathrm{H}$ bond length in $\mathrm{ZnH}^{+}{ }^{17}$ The calculated equilibrium bond distance of $\mathrm{CnH}$ has been found to be $166.2 \mathrm{pm}$, notably shorter than that of $\mathrm{HgH}, 173.8$ pm. ${ }^{18}$ In that work, a bond dissociation energy of $0.42 \mathrm{eV}$ in $\mathrm{CnH}$ was also reported, close to the experimental value of $0.46 \mathrm{eV}$ in $\mathrm{HgH}$.

Experimental studies of superheavy-element complexes are demanding, since most of them are radioactive and with very short half-lifes, which comes as an additional concern to 
the toxicity of cyanide, and there have been very few studies carried out to confirm that the superheavy element complexes in general behave like the lighter-element analogues. Moreover, studies reporting the chemistry of some complexes of Ds and Cn are conflicting. For instance, studies on Cn suggest mercury-like properties, ${ }^{18,19}$ whereas other studies suggest noble-gas-like behavior, mainly due to the strong relativistic contraction of the 7 s orbital. ${ }^{20,21}$

Exploring the properties of complexes of the superheavy elements using relativistic theoretical calculations is therefore important to understand their chemistry and our understanding of the chemistry of the super-heavy elements in general. In this study we report the structural parameters, vibrational frequencies, bond dissociation energies and electronic absorption spectra of mono- and dicyanide complexes of darmstadtium, roentgenium and copernicium. We compare the calculated properties of these complexes with the corresponding properties of the known cyanides of platinum, gold and mercury.

\section{METHODOLOGY}

The two-component spin-orbit zeroth-order regular approximation (SO-ZORA, in the following denoted simply as $2 \mathrm{C})^{22,23}$ as implemented in the Amsterdam density functional $(\mathrm{ADF})^{24}$ and the four-component Dirac-Kohn-Sham (DKS) relativistic density functional theory (DFT) as implemented in the ReSpect ${ }^{25}$ program packages were used to optimize the molecular structures. For the calculations performed in ADF, we used the PBE (Perdew, Burke and Ernzerhof) functional ${ }^{26}$ combined with all-electron triple- $\zeta$ double polarized (TZ2P) and quadruple- $\zeta$ quadruple polarized (QZ4P) Slater-type basis sets, all optimized for relativistic computations ${ }^{27}$. To ensure that the optimized geometries are real minima, frequency calculations were performed at the same level of theory as the geometry optimizations in ADF. For the geometry optimizations performed using the four-component relativistic program package ReSpect $^{25}$ (denoted as $4 \mathrm{C}$ in the following), the PBE functional and the uncontracted all-electron Dyall's relativistic basis sets (core-valence double- $\zeta$, denoted as unc-dyall-cvdz, and valence triple- $\zeta$, denoted as unc-dyall-cvtz), ${ }^{28-31}$ were used. The potential energy surface (PES) scans were obtained from calculations performed using the four-component relativistic program package ReSpect ${ }^{25}$ employing the PBE functional ${ }^{26}$ 
and the uncontracted dyall-cvtz basis set. ${ }^{28-32}$ This latter level of theory is also used to calculate the bond dissociation energies (BDE). The electronic absorption spectra were calculated using the SO-ZORA/PBE/QZ4P level of theory.

\section{RESULTS}

\section{Group 10: Platinum and Darmstadtium}

The ground-state electronic configuration of darmstadtium is reported ${ }^{33}$ to be $6 d_{3 / 2}^{4} 6 d_{5 / 2}^{4} 7 s^{2}$, which is different from that of platinum $\left(5 d_{3 / 2}^{4} 5 d_{5 / 2}^{5} 6 s^{1}\right)$ due to relativistic stabilization of the $7 \mathrm{~s}$ orbital. Thus, in contrast to platinum, darmstadtium has the expected energy ordering of the atomic orbitals. Based on the properties of the group 10 elements, darmstadtium (Ds) is expected to have $+6,+4$, and +2 oxidation states. However, its neutral state is predicted to be the most stable and it is expected to be a noble metal (with closed-shell ground-state electronic configuration). ${ }^{19}$ Our study shows that its cyanide complexes are structurally similar to those of the lighter members of the group. The PES plots for the bond formation reaction of platinum and darmstadtium monocyanides are shown in Figure1. The plots for $\mathrm{DsCN}$ and $\mathrm{DsCN}^{-}$show a minimum on the PES, which is not the case for $\mathrm{DsCN}^{+1}$. This indicates that $\mathrm{Ds}^{0}$ and $\mathrm{Ds}^{+2}$ are more stable than $\mathrm{Ds}^{+1}$.

The optimized bond lengths are collected in Table 1. The Ds-C bond in $\mathrm{DsCN}^{-}$is shorter than that of DsCN, that is, the neutral state of Ds forms a stronger Ds-C bond than the other oxidation states when it forms a complex with the cyanide anion. Among the known cyanide complexes of platinum is $\mathrm{PtCN}^{+}$. For this complex, geometry optimization using SO-ZORA/PBE/QZ4P gave a Pt-C bond length of $185.58 \mathrm{pm}$. This is in contrast to Ds, where only DsCN and $\mathrm{DsCN}^{-}$have a minimum on the PES (see Figure 1). For $\mathrm{PtCN}^{+}$, the Pt-C bond length is shorter than that of the sum of atomic single-bond radii of the atoms, ${ }^{34}$ thus indicating multiple-bond character. This multiple-bond character is observed in all the Pt and Ds complexes. For instance, the sum of the atomic single-bond radii of $\mathrm{Pt}$ and $\mathrm{C}$ in $\mathrm{PtCN}^{+}$is $198.00 \mathrm{pm}$, whereas our SO-ZORA/PBE/QZ4P value is $185.58 \mathrm{pm}$, a difference of $12.42 \mathrm{pm}$. The dicyanide complexes, $\mathrm{Pt}(\mathrm{CN})_{2}$ and $\mathrm{Ds}(\mathrm{CN})_{2}{ }^{2-}$, are found to 
be stable and both show multiple bond character. The metal-carbon bond lengths of the dicyanide complexes are longer than in the monocyanides, but are still shorter than the sum of the single-bond atomic radii (see Table 2). For both the mono and dicyanides, the optimized structures of the platinum complexes obtained using different levels of theory are in good agreement with each other and with available experimental data.

The vibrational frequencies for the monocyanides and dicyanides are listed in Table 1 and Table 2, respectively. The effect of the second $\mathrm{CN}^{-}$on the vibrational frequencies of $\mathrm{Ds}(\mathrm{CN})_{2}{ }^{2-}$ is small when compared to the other complexes. For example, the change in $\omega_{1}$ is $2.7 \mathrm{~cm}^{-1}$ for $\mathrm{Ds}(\mathrm{CN})_{2}{ }^{2-}$ and $59.4 \mathrm{~cm}^{-1}$ for $\mathrm{Pt}(\mathrm{CN})_{2}$ with respect to that of the corresponding monocyanides. Both the symmetric and unsymmetric bending modes of M$\mathrm{C}-\mathrm{N}$ are decreased compared to the monocyanides.

The total interaction and bond dissociation energies of the mono and dicyanides are listed in Table 3. DsCN- has a bond dissociation energy of $2.79 \mathrm{eV}$, whereas DsCN has 3.94 $\mathrm{eV}$, indicating that $\mathrm{DsCN}$ forms a slightly stronger bond than $\mathrm{PtCN}^{+}$. This is even more pronounced for the dicyanide complexes, which is also evident from the visualization of the orbitals involved in bond formation (see Table 3 and Figure 2). Furthermore, the calculated absorption spectra presented in Figure 3 show that $\mathrm{Pt}(\mathrm{CN})_{2}$ has one intense absorption peak around $590 \mathrm{~nm}$, whereas $\mathrm{Ds}(\mathrm{CN})_{2}{ }^{2-}$ shows intense absorption peaks between $200 \mathrm{~nm}$ and $300 \mathrm{~nm}$.

\section{Group 11: Gold and Roentgenium}

The valence s-subshell of $\mathrm{Rg}$ is expected to be relativistically more contracted and is predicted to have a $6 d_{3 / 2}^{4} 6 d_{5 / 2}^{5} 7 s^{2}$ electronic configuration, ${ }^{33}$ unlike the $5 d_{3 / 2}^{4} 5 d_{5 / 2}^{6} 6 s^{1}$ ground-state electronic configuration of gold. However, both the two-component and four-component closedshell relativistic geometry optimization showed that $\mathrm{RgCN}$ was formed analogously to $\mathrm{AuCN}$ (see Figure 4). The $\mathrm{Rg}-\mathrm{C}$ bond length is shorter than that of $\mathrm{Au}-\mathrm{C}$; the DKS/PBE/dyallcvtz optimized $\mathrm{Au}-\mathrm{C}$ bond length is $189.18 \mathrm{pm}$, while that of $\mathrm{Rg}-\mathrm{C}$ is $187.16 \mathrm{pm}$, see Ta-

ble 1. Our $\mathrm{Au}-\mathrm{C}$ bond length falls inbetween the result obtained preivously for $\mathrm{AuCN}$ using MP2/cc-pVQZ (186.51 pm) and using CCSD(T)/cc-pVQZ /191.05 pm). ${ }^{6}$ In both AuCN and 
RgCN, the metal-carbon bonds show multiple bond character, all considerably shorter than the sum of the single-bond atomic radii reported by Pyykkö. ${ }^{34}$ For instance, in AuCN the sum of the single-bond atomic radii between $\mathrm{Au}$ and $\mathrm{C}$ is $199.00 \mathrm{pm}, 9.82 \mathrm{pm}$ longer than our calculated DKS/PBE/dyall-cvtz bond length. The PES plots in Figure 4 as well as the structural parameters in Table 1 show no noticeable differences in the nature of the bonding in $\mathrm{AuCN}$ and $\mathrm{RgCN}$. Similar observations are made for the dicyanides.

The calculated $\mathrm{Au}-\mathrm{C}$ stretching frequency of $\mathrm{AuCN}$ (Table 1) is $480.6 \mathrm{~cm}^{-1}$, in excellent agreement with the experimental frequency $480.0 \mathrm{~cm}^{-1}$. Also the $\mathrm{C}-\mathrm{N}$ stretching and $\mathrm{Au}-\mathrm{C}-\mathrm{N}$ bending modes are in fair agreement with available experimental values. However, as we are comparing calculated harmonic frequencies with experimental fundamental frequencies, this agreement is potentially fortuitous considering that some of the experimental frequencies are actually larger than the calculated harmonic frequencies. However, this may due to the difference in the calculated and experimental bond lengths, which are slightly overestimated in our calculations. Nevertheless, Lee et al. ${ }^{35}$ reported calculated CCSD(T) harmonic frequencies of 2179,259 and $478 \mathrm{~cm}^{-1}$ respectively for the $\mathrm{C}-\mathrm{N}, \mathrm{Au}-\mathrm{C}-\mathrm{N}$ and $\mathrm{Au}-\mathrm{C}$ vibrational frequencies in $\mathrm{AuCN}$. Zaleski-Ejgierd et al. ${ }^{6}$ also reported $\mathrm{CCSD}(\mathrm{T}) / \mathrm{cc}-$ pVQZ calculated values of 2181, 285 and $472 \mathrm{~cm}^{-1}$, respectively and these latter results are claimed to be more accurate than the available experimental estimates for AuCN. ${ }^{6}$ Recently, Hill et al. ${ }^{2}$ also reported values of $2203.8,284.1$ and $485.2 \mathrm{~cm}^{-1}$, respectively for the C-N, $\mathrm{Au}-\mathrm{C}-\mathrm{N}$ and $\mathrm{Au}-\mathrm{C}$ vibrational frequencies in $\mathrm{AuCN}$, calculated using the explicitly correlated CCSD(T)-F12b method. All these previously reported values for AuCN are in good agreement with our calculated values listed in Table 1, lending additional support to the claim that the quality of the experimental vibrational frequencies may be somewhat low.

The total interaction and bond dissociation energies of the $\mathrm{Au}$ and $\mathrm{Rg}$ mono and dicyanides are listed in Table 3. The results for the monocyanides show a difference of $0.60 \mathrm{eV}$ between $\mathrm{AuCN}$ and $\mathrm{RgCN}$, whereas for the dicyanides the difference is very small. The bond dissociation energies for $\mathrm{AuCN}$ and $\mathrm{Au}(\mathrm{CN})_{2}^{-}$are in good agreement with the previously reported CCSD(T) and MP2 results; ${ }^{36} 3.85 \mathrm{eV}$ and $4.27 \mathrm{eV}$ for $\mathrm{AuCN}$, respectively, and 4.37 $\mathrm{eV}$ and $4.72 \mathrm{eV}$, respectively for $\mathrm{Au}(\mathrm{CN})_{2}^{-}$(see Table 3). Overall, our results show that the $\mathrm{Rg}$ complexes behave like the Au complexes. The MO diagrams shown in Figure 5 also 
support a multiple bond character for the $\operatorname{Rg}(\mathrm{CN})_{2}^{-}$complex. Moreover, the electronic absorption spectra presented in Figure 3 show that both $\mathrm{Au}(\mathrm{CN})_{2}^{-}$and $\operatorname{Rg}(\mathrm{CN})_{2}^{-}$have intense absorption peaks around 200-220 nm.

\section{Group 12: Mercury and Copernicium}

Spin-orbit coupling leads to a stabilization of the $7 \mathrm{~s}$ and destabilization of the $6 \mathrm{~d}$ orbitals also in the case of copernicium, giving it a $6 d_{3 / 2}^{4} 6 d_{5 / 2}^{6} 7 s^{2}$ electronic configuration ${ }^{33}$. Hence, the $6 \mathrm{~d}$ electrons can be expected to be more involved in oxidation and chemical bonding than the $7 \mathrm{~s}$ electrons because of the relativistic effects. For instance, $\mathrm{Cn}^{+}$gets a $6 d_{3 / 2}^{4} 6 d_{5 / 2}^{5} 7 s^{2}$ electronic ground-state configuration, in contrast to $\mathrm{Hg}^{+}$which has a $5 d_{3 / 2}^{4} 6 d_{5 / 2}^{6} 7 s^{1}$ electronic configuration. However, once $\mathrm{Cn}^{+}$is formed, one can consider two possible electronic configurations: $6 \mathrm{~d}^{10} 7 \mathrm{~s}^{1}$ and $6 \mathrm{~d}^{9} 7 \mathrm{~s}^{2}$. Dirac-Hartree-Fock (DF) calculations ${ }^{17}$ suggest that these two electronic configurations of $\mathrm{Cn}^{+}$are nearly degenerate. Hence, $\mathrm{Cn}^{2+}$ gets a favored $6 \mathrm{~d}^{10}$ electronic configuration as is the case for $\mathrm{Hg}^{2+}$. For this reason, the PES of three different oxidation states of copernicium monocyanide were analyzed, of which only $\mathrm{CnCN}^{+}$can be expected to exist, similar to the existence of $\mathrm{HgCN}^{+}$. The PES plot shown in Figure 6 also shows the complex formation of $\mathrm{HgCN}^{+}$and $\mathrm{CnCN}^{+}$. These are in good agreement with the experimental study reported by Eichler et al. ${ }^{37}$ who concluded that the stronger adsorption interaction of $\mathrm{Cn}$ with gold involves the formation of a metal bond, which is a typical behavior of group 12 elements. Moreover, the behavior of $\mathrm{Cn}$ observed in this study is in agreement with previous theoretical studies of other copernicium complexes. ${ }^{1,38-40}$

The optimized geometry of $\mathrm{HgCN}^{+}$(Table 1) is in fair agreement with the experimental structural parameters. It is noteworthy that the $\mathrm{Hg}-\mathrm{C}$ bond in $\mathrm{HgCN}$ is longer than that of $\mathrm{HgCN}^{+}$. For example, Filatov and Cremer ${ }^{41}$ obtained a bond length of $211.40 \mathrm{pm}$ using the infinite-order regular approximation with modified metric (IORAmm/QCISD) in HgCN (open shell), while that of $\mathrm{Hg}-\mathrm{C}$ in $\mathrm{HgCN}^{+}$(closed shell) obtained from the DKS/dyallcvtz calculation in our study is $198.31 \mathrm{pm}$. A test calculation using Lévy-Leblond DFT (PBE/dyall-cvtz) in DIRAC ${ }^{42}$ gave a $\mathrm{Hg}_{-} \mathrm{C}$ bond distance of $216.36 \mathrm{pm}$ for $\mathrm{HgCN}^{+}$, whereas the Dirac-Coulomb four-component calculation gave $198.31 \mathrm{pm}$, resulting in a relativistic 
contraction of $18.05 \mathrm{pm}$. Both these monocyanides show multiple-bond character. Moreover, Cn forms a stronger bond to $\mathrm{CN}^{-}$than $\mathrm{Hg}$, the DKS/dyall-cvtz optimized Hg-C bond length in $\mathrm{HgCN}^{+}$is for instance $198.31 \mathrm{pm}$ whereas that of $\mathrm{Cn}-\mathrm{C}$ in $\mathrm{CnCN}^{+}$is $191.15 \mathrm{pm}$ (a difference of $7 \mathrm{pm}$, Table 1). Our optimized geometry for $\mathrm{Hg}(\mathrm{CN})_{2}$ is also in good agreement with experimental data (Table 2), and that of $\mathrm{Cn}(\mathrm{CN})_{2}$ is longer than the sum of the singlebond atomic radii between $\mathrm{Cn}$ and $\mathrm{C}$, indicating a loose bond compared to that of $\mathrm{Hg}(\mathrm{CN})_{2}$. However, the visualization of the MOs shows the overlap of orbitals (Figure 7), an indication for a possible formation of a bond between copernicium and carbon. Test calculations for $\mathrm{Cn}(\mathrm{NC})_{2}$, diisocyanide, predict a slightly shorter Cn-N bond compared to the sum of the single-bond atomic radii between $\mathrm{Cn}$ and $\mathrm{N}$.

The vibrational frequencies calculated for the monocyanides and dicyanides are listed in Table 1 and Table 2, respectively. The differences between the vibrational frequencies for both the mono and dicyanide complexes of $\mathrm{Hg}$ and $\mathrm{Cn}$ are not large. However, there is an increase in the vibrational frequency for all modes going from $\mathrm{Hg}$ to $\mathrm{Cn}$. For instance, $\omega_{1}$ for $\mathrm{Hg}(\mathrm{CN})_{2}$ is $460.7 \mathrm{~cm}^{-1}$ whereas that of $\mathrm{Cn}(\mathrm{CN})_{2}$ is $487.2 \mathrm{~cm}^{-1}$. There is good agreement between our calculated $\omega_{2}$ value and the available experimental value for $\mathrm{Hg}(\mathrm{CN})_{2}$.

The total interaction and bond dissociation energies of the mono and dicyanides are listed in Table 3. The bond dissociation energy for $\mathrm{HgCN}$ (open shell, and $215.90 \mathrm{pm} \mathrm{Hg-C}$ bond length) calculated using $\operatorname{CCSD}(\mathrm{T})$ by Cremer et al. is $2.41 \mathrm{eV}{ }^{4}$ In our calculations for $\mathrm{HgCN}^{+}$(closed shell and a $\mathrm{Hg}-\mathrm{C}$ bond length of $198.31 \mathrm{pm}$ ), we got a BDE of $2.51 \mathrm{eV}$. Considering a $17.59 \mathrm{pm}$ bond length difference between the complexes, this gives confidence that our calculated BDE for the complexes are accurate. For $\mathrm{Hg}(\mathrm{CN})_{2}$, the bond dissociation energy is $4.54 \mathrm{eV}$ and very close to that of $\mathrm{Cn}(\mathrm{CN})_{2}, 4.56 \mathrm{eV}$. The total interaction energies also show no considerable differences between the $\mathrm{Hg}$ and $\mathrm{Cn}$ complexes. The electronic absorption spectra presented in Figure 3 indicate that $\mathrm{Hg}(\mathrm{CN})_{2}$ absorbs light at around 225 $\mathrm{nm}$, whereas $\mathrm{Cn}(\mathrm{CN})_{2}$ absorbs at around $247 \mathrm{~nm}$. 


\section{CONCLUSIONS}

In this work, we have studied the $\mathrm{XCN}$ and $\mathrm{X}(\mathrm{CN})_{2}(\mathrm{X}=\mathrm{Pt}, \mathrm{Ds}, \mathrm{Au}, \mathrm{Rg}, \mathrm{Hg}$ and $\mathrm{Cn})$ molecules in different oxidation states. The monocyanides of roentgenium and copernicium behave as the lighter members of these groups, whereas darmstadtium prefers to form a complex in its neutral state, in contrast to platinum. The $\mathrm{Rg}-\mathrm{C}$ and $\mathrm{Cn}-\mathrm{C}$ bond lengths of the monocyanide complexes are shorter than the $\mathrm{Au}-\mathrm{C}$ and $\mathrm{Hg}-\mathrm{C}$ bonds, whereas it is the opposite for Ds-C and Pt-C. Visualization of the orbital overlaps supports the notion that these superheavy-element cyanide complexes form multiple-bonds. The optimized structural parameters of $\mathrm{Pt}(\mathrm{CN})_{2}, \mathrm{Au}(\mathrm{CN})_{2}^{-}$and $\mathrm{Hg}(\mathrm{CN})_{2}$ are in good agreement with the corresponding experimental bond lengths, and we therefore also expect that the structural parameters calculated in this work for those complexes not observed experimentally give an accurate prediction of the expected structure. With the exception of $\mathrm{RgCN}$, the metal-carbon stretching frequencies decrease as the metals become heavier for all molecules, whereas the reverse trend is observed for the $\mathrm{C}-\mathrm{N}$ stretching frequencies. Our calculated vibrational frequencies for $\mathrm{AuCN}$ are in fairly good agreement with previously reported experimental and theoretical vibrational frequencies of this complex, suggesting that the vibrational frequencies calculated for the complexes should give fairly accurate predictions of these vibrational frequencies. The overall analyses indicate that $\mathrm{Ds}, \mathrm{Rg}$ and $\mathrm{Cn}$ can form stable complexes with strong bonds with the cyanide ion, and in some cases even stronger bonds than the complexes of the lighter group members.

\section{ACKNOWLEDGMENTS}

This work has received support from the Research Council of Norway through a Centre of Excellence Grant (Grant No. 179568/ V30). This work has also received support from the Norwegian Supercomputing program NOTUR (Grant No. NN4654K). 


\section{References}

1. V. Pershina and T. Bastug, Chem. Phys. 311, 139150 (2005).

2. J. G. Hill, A. O. Mitrushchenkov, and K. A. Peterson, J. Chem. Phys. 138, 134314 (2013).

3. T. Okabayashi, T. Yamamoto, E. Y. Okabayashi, and M. Tanimoto, J. Phys. Chem. A 115, 1869 (2011).

4. D. Cremer, E. Kraka, and M. Filatov, ChemPhysChem 9, 25102521 (2008).

5. W. Liu and C. van Wüllen, J. Chem. Phys. 110, 3730 (1999).

6. P. Zaleski-Ejgierd, M. Patzschke, and P. Pyykkö, J. Chem. Phys. 128, 224303 (2008).

7. M. Filatov, Chem. Phys. Lett. 373, 131135 (2003).

8. T. Rose, Nature 55, 448 (1897).

9. M. G. Nicol, C. A. Fleming, and R. L. Paul, in The Extractive Metallurgy of Gold in South Africa, edited by G. G. Stanley (The South African Institute of Mining and Metallurgy, 1987), vol. M7 of The South African Institute of Mining and Metallurgy Monograph Series.

10. S. J. Hibble, A. M. Chippindale, E. J. Bilbe, E. Marelli, P. J. Harris, and A. C. Hannon, Inorg. Chem. 50, 104 (2011).

11. The Merck Index, vol. 10 (Merck Co. Inc., Rahway, New Jersey, 1983).

12. M. L. Benaissa, P. Hantson, C. Bismuth, and F. J. Baud, Intensive Care Med. 21, 1051 (1995).

13. M. Patzschke and P. Pyykkö, Chem. Commun. pp. 1982-1983 (2004).

14. V. Pershina, in The Chemistry of Superheavy Elements, edited by M. Schädel (Springer US, 2003), pp. 31-94, ISBN 978-1-4020-1250-1. 
15. J. T. Waber and F. W. Averill, J. Chem. Phys. 60, 4466 (1974).

16. J. Thayer, in Relativistic Methods for Chemists, edited by M. Barysz and Y. Ishikawa (Springer Netherlands, 2010), vol. 10 of Challenges and Advances in Computational Chemistry and Physics, pp. 63-97, ISBN 978-1-4020-9974-8.

17. M. Seth, P. Schwerdtfeger, and M. Dolg, J. Chem. Phys. 106, 3623 (1997).

18. N. S. Mosyagin, T. A. Isaev, and A. V. Titov, J. Chem. Phys. 124, 224302 (2006).

19. B. Eichler, Kernenergie 19, 307311 (1976).

20. K. S. Pitzer, J. Chem. Phys. 63, 1033 (1975).

21. J. Anton, B. Fricke, and P. Schwerdtfeger, Chem. Phys. 311, 97 (2005).

22. E. van Lenthe, E. J. Baerends, and J. G. Snijders, J. Chem. Phys. 101, 9783 (1994).

23. E. van Lenthe, A. Ehlers, and E. J. Baerends, J. Chem. Phys. 110, 8943 (1999).

24. E. J. Baerends, J. Autschbach, A. Berces, F. M. Bickelhaupt, C. Bo, P. M. Boerrigter, L. Cavallo, D. P. Chong, L. Deng, R. M. Dickson, et al., ADF2014.01, SCM, Theoretical Chemistry, Vrije Universiteit, Amsterdam, The Netherlands, http://www.scm.com (2014).

25. ReSpect, version 3.3.0 (beta), 2013; Relativistic Spectroscopy DFT program of authors S. Komorovsky, M. Repisky, V. G. Malkin, O. L. Malkina, M. Kaupp, K. Ruud, with contributions from R. Bast, U. Ekström, S. Knecht, I. Malkin Ondik, E. Malkin, see www.respectprogram.org.

26. J. P. Perdew, K. Burke, and M. Ernzerhof, Phys. Rev. Lett. 77, 3865 (1996).

27. E. van Lenthe and E. J. Baerends, J. Comput. Chem. 24, 1142 (2003).

28. K. G. Dyall, Unpublished Basis Sets for $2 p$ - 3p Elements, Available from the Dirac web site, http://dirac.chem.sdu.dk.

29. K. G. Dyall, Theor. Chem. Acc. 117, 483 (2007). 
30. K. G. Dyall, Theor. Chem. Acc. 112, 403 (2004).

31. K. G. Dyall and A. S. P. Gomes, Theor. Chem. Acc. 125, 97 (2009).

32. K. Dyall, Theor. Chem. Acc. 129, 603 (2011), ISSN 1432-881X.

33. J. T. Waber, D. T. Cromer, and D. Liberman, J. Chem. Phys. 51, 664 (1969).

34. P. Pyykkö, J. Phys. Chem. A 119, 2326 (2015).

35. D. Lee, I. S. Lim, Y. S. Lee, D. Hagebaum-Reignier, and G.-H. Jeung, J. Chem. Phys. 126, 244313 (2007).

36. P. Schwerdtfeger and M. Lein, in Gold Chemistry, edited by F. Mohr (Wiley-VCH Verlag GmbH and Co. KGaA, Weinheim, Germany, 2009), pp. 183-247, ISBN 9783527626724, URL http://dx.doi.org/10.1002/9783527626724.ch4.

37. R. Eichler, N. V. Aksenov, A. V. Belozerov, G. A. Bozhikov, V. I. Chepigin, S. N. Dmitriev, R. Dressler, H. W. Gäggeler, V. A. Gorshkov, F. Haenssler, et al., Nature 447, $72(2007)$.

38. V. Pershina, T. Bastug, T. Jacob, B. Fricke, and S. Varga, Chem. Phys. Lett. 365, $176183(2002)$.

39. C. Sarpe-Tudoran and et al., Eur. Phys. J. 24, 6567 (2003).

40. N. Gaston, I. Opahle, H. Gäggeler, and P. Schwerdtfeger, Angew. Chem. Int. Ed. 46, 1663 (2007), ISSN 1521-3773.

41. M. Filatov and D. Cremer, J. Chem. Phys. 121, 5618 (2004).

42. DIRAC, a relativistic ab initio electronic structure program, Release DIRAC14 (2014), written by T. Saue, L. Visscher, H. J. Aa. Jensen, and R. Bast, with contributions from V. Bakken, K. G. Dyall, S. Dubillard, U. Ekström, E. Eliav, T. Enevoldsen, E. Faßhauer, T. Fleig, O. Fossgaard, A. S. P. Gomes, T. Helgaker, J. Henriksson, M. Iliaš, Ch. R. Jacob, S. Knecht, S. Komorovsky, O. Kullie, C. V. Larsen, J. K. Laerdahl, Y. S. Lee, H. S. Nataraj, P. Norman, G. Olejniczak, J. Olsen, Y. C. Park, J. K. Pedersen, M. 
Pernpointner, R. di Remigio, K. Ruud, P. Saek, B. Schimmelpfennig, J. Sikkema, A. J. Thorvaldsen, J. Thyssen, J. van Stralen, S. Villaume, O. Visser, T. Winther, and S. Yamamoto (see http://www.diracprogram.org). 
Figure 1: Potential energy surfaces for the complex formation reaction between platinum and darmstadtium with cyanide ion. Calculated using PBE/dyall-cvtz and four-component relativistic approach. The total energy at the minimum is subtracted from the total energies at each point.

Figure 2: Frontier molecular orbitals (MOs) of $\mathrm{Ds}(\mathrm{CN})_{2}$ obtained from Bader analysis using ZORA/PBE/QZ4P calculations. The MOs responsible for bond formation highlighted using box 1 is a mixture of $\mathrm{d}_{x z}$ of Ds, $\mathrm{p}_{x}$ of both $\mathrm{C}$ and $\mathrm{N}$; that in box 2 is a mixture of $\mathrm{p}_{z}$ of both Ds, C and $\mathrm{N}$; whereas that in box 3 is a mixture of $\mathrm{d}_{x z}$ of Ds and $\mathrm{p}_{x}$ of both $\mathrm{C}$ and $\mathrm{N}$.

Figure 3: Absorption spectra of the dicyanide complexes calculated using SOZORA/PBE/QZ4P 
Figure 4: Potential energy surfaces for the complex formation reaction between gold and roentgenium with cyanide ion. Calculated using PBE/dyall-cvtz and four-component relativistic approach. The total energy at the minimum is subtracted from the total energies at each point.

Figure 5: Frontier molecular orbitals (MOs) of $\operatorname{Rg}(\mathrm{CN})_{2}^{-}$obtained from Bader analysis using SO-ZORA/PBE/QZ4P calculations. The MOs responsible for bond formation highlighted using box 1 is a mixture of $\mathrm{d}_{x z}$ of $\mathrm{Rg}, \mathrm{p}_{x}$ of both $\mathrm{C}$ and $\mathrm{N}$; that in box 2 is a mixture of $\mathrm{d}_{y z}$ of $\mathrm{Rg}, \mathrm{p}_{y}$ of both $\mathrm{C}$ and $\mathrm{N}$; whereas that in box 3 is a mixture of $\mathrm{d}_{x z}$ of $\mathrm{Rg}$ and $\mathrm{p}_{x}$ of both $\mathrm{C}$ and $\mathrm{N}$.

Figure 6: Potential energy surfaces for the complex formation reaction between mercury and copernicium with cyanide ions. Calculated using PBE/dyall-cvtz and four-component relativistic approach. The total energy at the minimum is subtracted from the total energies at each point. 
Figure 7: Frontier molecular orbitals (MOs) of $\mathrm{Cn}(\mathrm{CN})_{2}$ obtained from Bader analysis using SO-ZORA/PBE/QZ4P calculations.The MOs responsible for bond formation highlighted using box 1 is a mixture of $\mathrm{p}_{z}$ of $\mathrm{Cn}, \mathrm{C}$ and $\mathrm{N}$; that in box 2 is a mixture of $\mathrm{d}_{x z}$ of $\mathrm{Cn}, \mathrm{p}_{x}$ of both $\mathrm{C}$ and $\mathrm{N}$; whereas that in box 3 is a mixture of $\mathrm{d}_{x z}$ of $\mathrm{Cn}$ and $\mathrm{p}_{x}$ of both $\mathrm{C}$ and $\mathrm{N}$. 

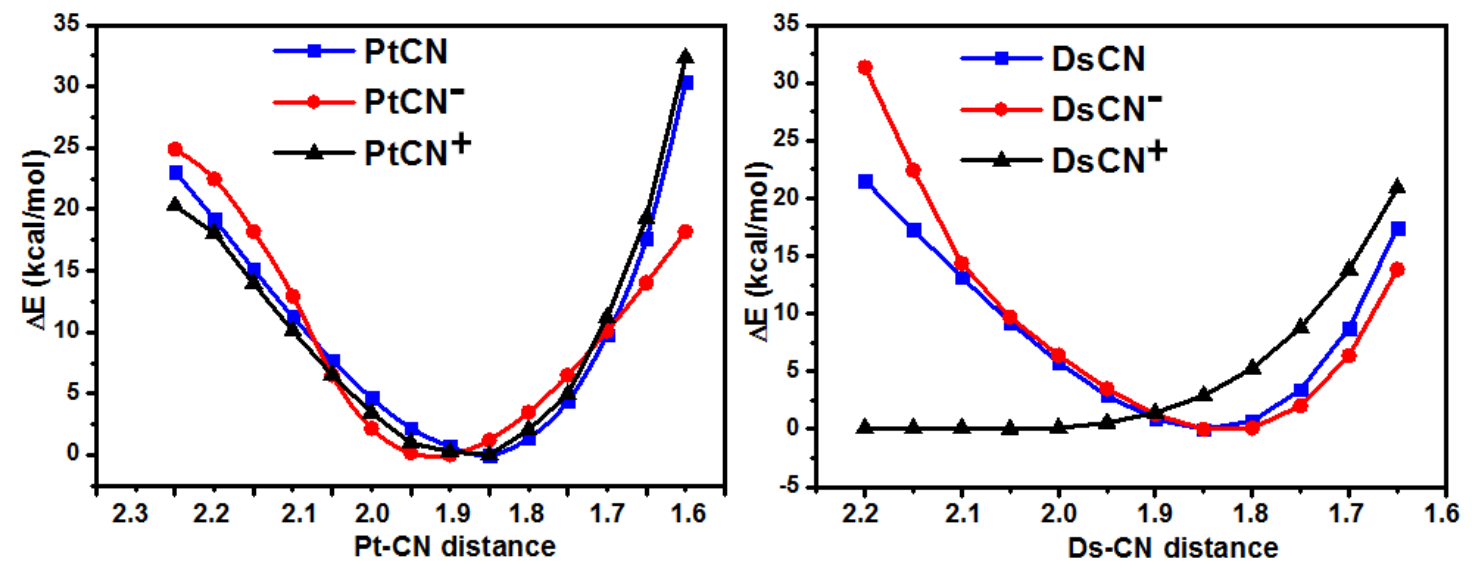

Figure 1

T. B. Demissie, K. Ruud

Int. J. Quant. Chem. 


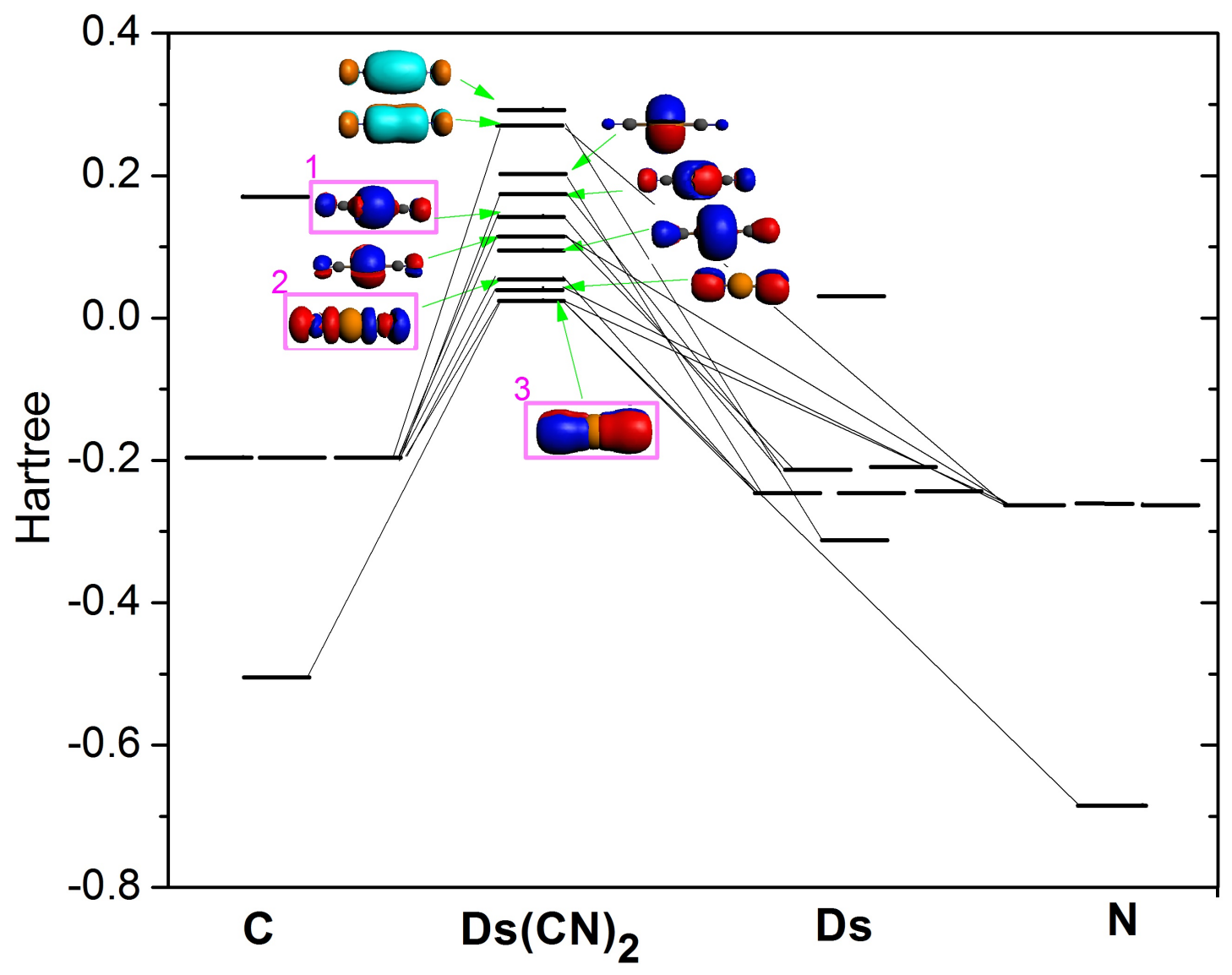

Figure 2

T. B. Demissie, K. Ruud

Int. J. Quant. Chem. 


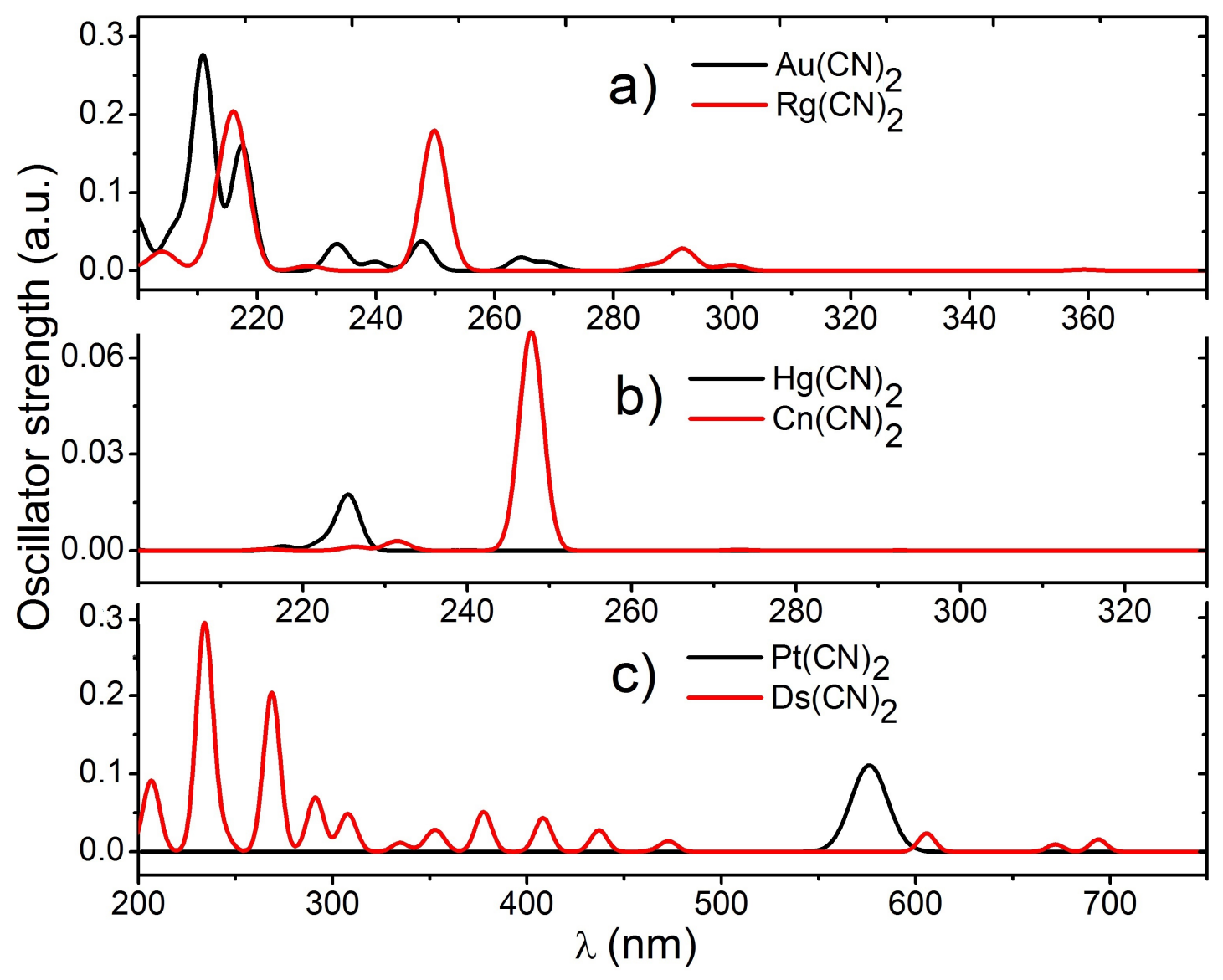

Figure 3

T. B. Demissie, K. Ruud

Int. J. Quant. Chem. 

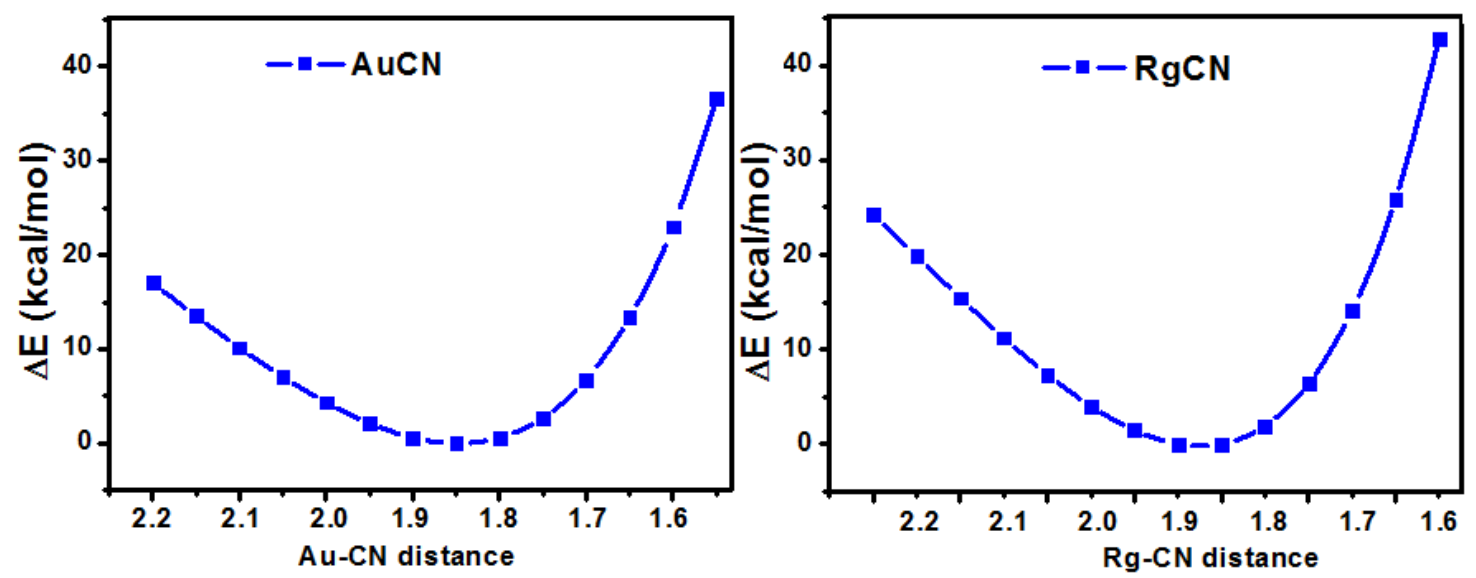

Figure 4

T. B. Demissie, K. Ruud

Int. J. Quant. Chem. 


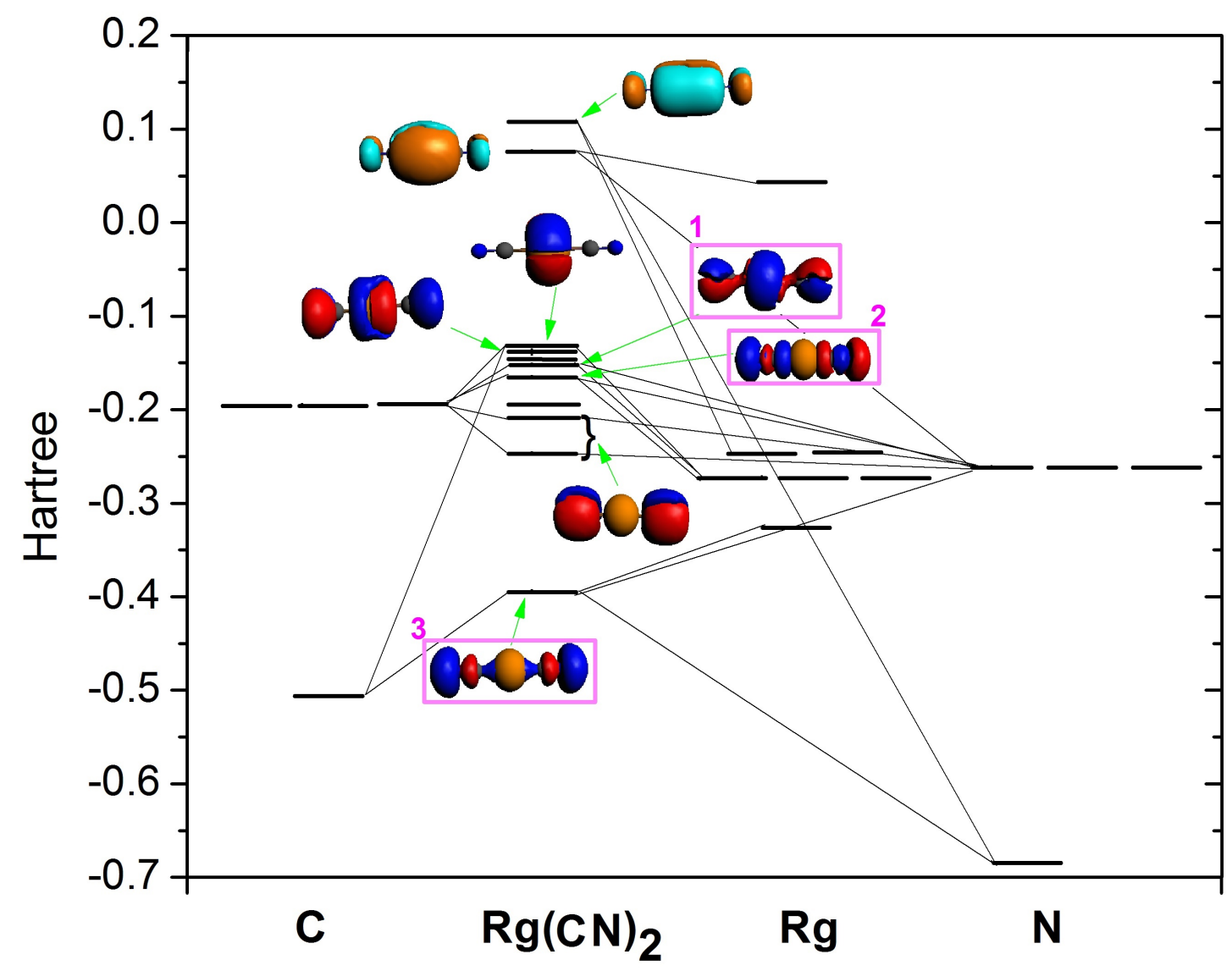

Figure 5

T. B. Demissie, K. Ruud Int. J. Quant. Chem. 

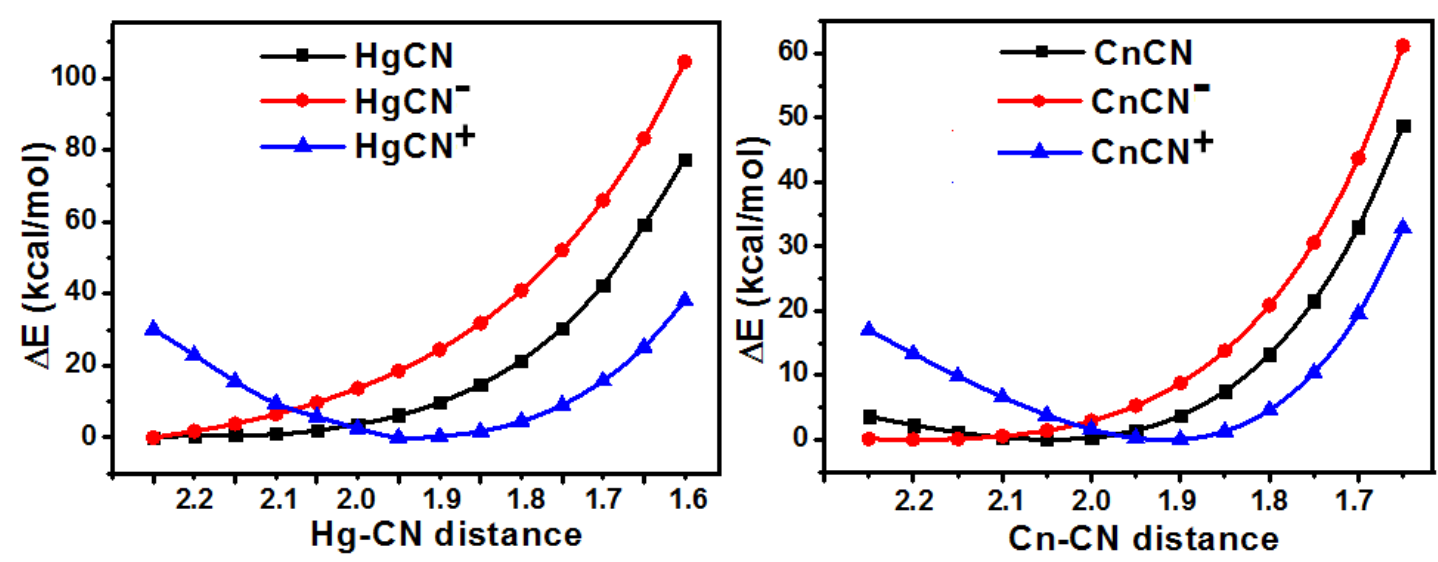

Figure 6

T. B. Demissie, K. Ruud

Int. J. Quant. Chem. 


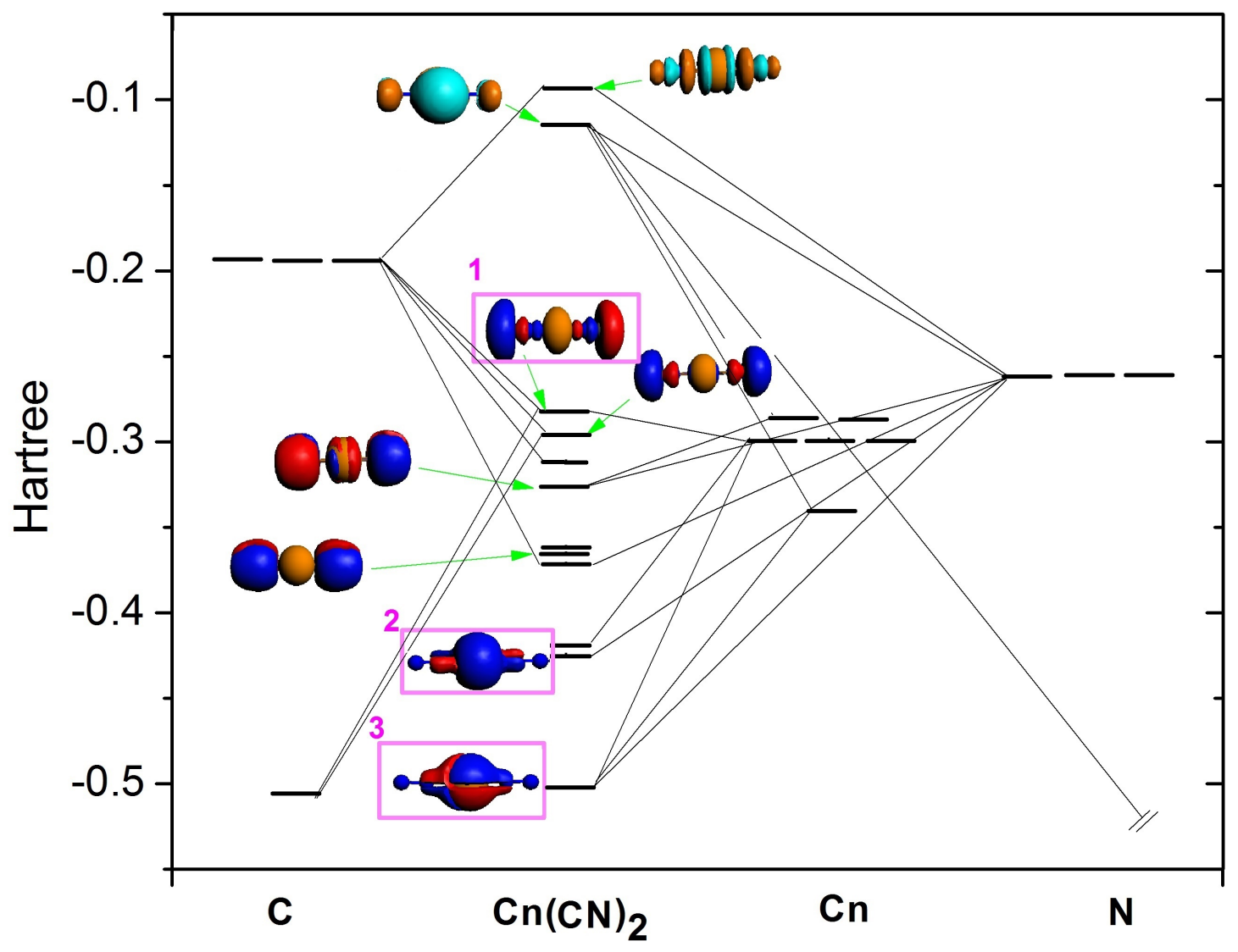

Figure 7

T. B. Demissie, K. Ruud Int. J. Quant. Chem. 
Table 1: Calculated and available experimental bond lengths (in $\mathrm{pm}$ ) and vibrational frequencies $\left(\mathrm{cm}^{-1}\right)$ of MCN molecules $(\mathrm{M}=\mathrm{Pt}$, Ds, $\mathrm{Au}, \mathrm{Rg}, \mathrm{Hg}$ and $\mathrm{Cn})$

\begin{tabular}{|c|c|c|c|c|c|c|c|c|}
\hline & Method $^{a}$ & $\mathrm{PtCN}^{+}$ & $\mathrm{DsCN}$ & $\mathrm{DsCN}^{-}$ & $\mathrm{AuCN}^{b}$ & $\mathrm{RgCN}$ & $\mathrm{HgCN}^{+}$ & $\mathrm{CnCN}^{+}$ \\
\hline \multicolumn{9}{|c|}{ Bond lengths (pm) } \\
\hline \multirow{6}{*}{$r_{e}(\mathrm{M}-\mathrm{C})$} & $2 \mathrm{C} / \mathrm{TZ} 2 \mathrm{P}$ & 185.74 & 189.43 & 187.15 & 190.34 & 187.70 & 199.62 & 192.88 \\
\hline & $2 \mathrm{C} / \mathrm{QZ} 4 \mathrm{P}$ & 185.58 & 189.43 & 187.18 & 190.13 & 186.51 & 199.18 & 191.55 \\
\hline & $4 \mathrm{C} / \mathrm{cvdz}$ & 185.52 & 189.28 & 187.16 & 189.62 & 187.38 & 198.98 & 191.82 \\
\hline & $4 \mathrm{C} / \mathrm{cvtz}$ & 185.14 & 189.17 & 187.13 & 189.18 & 187.16 & 198.31 & 191.15 \\
\hline & $\Sigma \operatorname{ar}^{c}$ & 198.00 & 203.00 & 203.00 & 199.00 & 196.00 & 208.00 & 197.00 \\
\hline & Exp. & 190.04 & - & - & 191.23 & - & 200.00 & - \\
\hline \multirow{6}{*}{$r_{e}(\mathrm{C}-\mathrm{N})$} & $2 \mathrm{C} / \mathrm{TZ} 2 \mathrm{P}$ & 119.03 & 117.66 & 119.17 & 116.85 & 117.50 & 116.72 & 117.23 \\
\hline & $2 \mathrm{C} / \mathrm{QZ} 4 \mathrm{P}$ & 118.56 & 117.84 & 119.26 & 116.90 & 117.54 & 116.71 & 117.32 \\
\hline & $4 \mathrm{C} / \mathrm{cvdz}$ & 118.97 & 118.27 & 119.80 & 117.32 & 118.02 & 117.13 & 117.82 \\
\hline & $4 \mathrm{C} / \mathrm{cvtz}$ & 118.75 & 118.08 & 119.36 & 116.96 & 117.79 & 116.75 & 117.46 \\
\hline & $\Sigma \operatorname{ar}^{c}$ & 114.00 & 114.00 & 114.00 & 114.00 & 114.00 & 114.00 & 114.00 \\
\hline & Exp. & 116.10 & - & - & 115.87 & - & - & - \\
\hline \multicolumn{9}{|c|}{ Vibrational frequencies $\left(\mathrm{cm}^{-1}\right)^{d}$} \\
\hline \multirow{5}{*}{$\omega 1$} & $2 \mathrm{C} / \mathrm{TZ} 2 \mathrm{P}$ & 510.3 & 549.5 & 545.7 & 479.8 & 559.4 & 411.6 & 495.1 \\
\hline & 2C/QZ4P & 527.8 & 518.6 & 540.1 & 480.6 & 534.1 & 421.1 & 485.6 \\
\hline & Exp. & - & - & - & 480.0 & - & - & - \\
\hline & & & & & 480.0 & & & \\
\hline & & & & & 598.0 & & & \\
\hline \multirow{4}{*}{$\omega 2$} & $2 \mathrm{C} / \mathrm{TZ} 2 \mathrm{P}$ & 1876.2 & 2103.5 & 1980.3 & 2176.1 & 2125.1 & 2201.4 & 2152.7 \\
\hline & 2C/QZ4P & 1971.5 & 2084.1 & 1964.2 & 2168.4 & 2114.0 & 2191.5 & 2138.9 \\
\hline & Exp. & - & - & - & 2236.0 & - & - & - \\
\hline & & & & & 2164.0 & & & \\
\hline \multirow{5}{*}{$\omega 3$} & $2 \mathrm{C} / \mathrm{TZ} 2 \mathrm{P}$ & 218.0 & 339.4 & 389.4 & 293.3 & 353.3 & 227.3 & 257.1 \\
\hline & $2 \mathrm{C} / \mathrm{QZ} 4 \mathrm{P}$ & 253.5 & 327.1 & 395.8 & 276.6 & 349.7 & 225.2 & 262.5 \\
\hline & Exp. & - & - & - & 320.0 & - & - & - \\
\hline & & & & & 272.0 & & & \\
\hline & & & & & 358.0 & & & \\
\hline
\end{tabular}

\footnotetext{
${ }^{a} 2 \mathrm{C}$ refers to the two component relativistic (SO-ZORA/PBE) and $4 \mathrm{C}$ refers to the four-component relativistic (DKS/PBE)

calculations.

${ }^{b} \mathrm{Au}-\mathrm{C}$ in $\mathrm{AuCN}$ using the $4 \mathrm{C} / \mathrm{cvqz}^{d}$ level is $189.22 \mathrm{pm}$, and $\mathrm{C}-\mathrm{N}$ is $116.98 \mathrm{pm}$.

${ }^{c}$ Sar is bond length calculated based on the atomic radii for single bond given by Pekka Pyykkö (the sum of atomic radii for $\mathrm{C}=\mathrm{N}$ double bond is $127 \mathrm{pm}){ }^{34}$

${ }^{d} \omega 1$ is M-C stretching, $\omega 2$ is C-N stretching, $\omega 3$ is M-C-N bending mode, all calculated using SO-ZORA/PBE.
} 
Table 2: Calculated and available experimental bond lengths (in pm) and vibrational frequencies $\left(\mathrm{cm}^{-1}\right)$ of $\mathrm{M}(\mathrm{CN})_{2}$ molecules $(\mathrm{M}=\mathrm{Pt}$, Ds, $\mathrm{Au}, \mathrm{Rg}, \mathrm{Hg}$ and $\mathrm{Cn})$

\begin{tabular}{|c|c|c|c|c|c|c|c|}
\hline & Method $^{a}$ & $\operatorname{Pt}(\mathrm{CN})_{2}^{b}$ & $\mathrm{Ds}(\mathrm{CN})_{2}^{2-}$ & $\mathrm{Au}(\mathrm{CN})_{2}^{-}$ & $\operatorname{Rg}(\mathrm{CN})_{2}^{-}$ & $\mathrm{Hg}(\mathrm{CN})_{2}$ & $\mathrm{Cn}(\mathrm{CN})_{2}$ \\
\hline \multicolumn{8}{|c|}{ Bond lengths (pm) } \\
\hline \multirow{5}{*}{$r_{e}(\mathrm{M}-\mathrm{C})$} & $2 \mathrm{C} / \mathrm{TZ} 2 \mathrm{P}$ & 196.03 & 199.15 & 198.35 & 199.04 & 200.60 & 200.37 \\
\hline & $2 \mathrm{C} / \mathrm{QZ} 4 \mathrm{P}$ & 195.46 & 198.35 & 198.29 & 198.20 & 200.00 & 198.99 \\
\hline & $4 \mathrm{C} / \mathrm{cvtz}$ & 195.37 & 198.21 & 197.88 & 198.15 & 200.00 & 198.68 \\
\hline & $\Sigma a r^{c}$ & 198.00 & 203.00 & 199.00 & 196.00 & 208.00 & 197.00 \\
\hline & Exp. & $197.9(1)$ & - & $199.9(32)$ & - & $201.9(3)$ & - \\
\hline \multirow{5}{*}{$r_{e}(\mathrm{C}-\mathrm{N})$} & $2 \mathrm{C} / \mathrm{TZ} 2 \mathrm{P}$ & 117.95 & 119.36 & 117.18 & 117.39 & 116.39 & 116.59 \\
\hline & 2C/QZ4P & 118.26 & 119.32 & 117.19 & 117.48 & 116.42 & 116.57 \\
\hline & $4 \mathrm{C} / \mathrm{cvtz}$ & 119.04 & 119.47 & 117.38 & 117.63 & 116.51 & 116.61 \\
\hline & $\sum \operatorname{ar}^{c}$ & 114.00 & 114.00 & 114.00 & 114.00 & 114.00 & 114.00 \\
\hline & Exp. & $115.76(8)$ & - & $112.0(39)$ & - & $116.0(3)$ & - \\
\hline
\end{tabular}

Vibrational frequencies $\left(\mathrm{cm}^{-1}\right)^{d}$

\begin{tabular}{|l|l|r|r|r|r|r|r|}
\hline & 2C/TZ2P & 431.8 & 544.8 & 434.5 & 495.9 & 453.3 & 475.1 \\
$\omega 1$ & 2C/QZ4P & 468.4 & 537.4 & 437.2 & 505.4 & 460.7 & 487.2 \\
& Exp. & - & - & 480.0 & - & - & - \\
\hline \multirow{3}{*}{$\omega 2$} & 2C/TZ2P & 2175.7 & 2002.2 & 2154.6 & 2066.5 & 2219.5 & 2205.0 \\
& 2C/QZ4P & 2151.6 & 1991.5 & 2145.6 & 2123.8 & 2216.9 & 2188.3 \\
& Exp. & 2217.0 & - & - & - & 2197.4 & - \\
\hline \multirow{3}{*}{$\omega 3$} & 2C/TZ2P & 459.9 & 490.3 & 410.2 & 411.4 & 351.5 & 439.9 \\
& 2C/QZ4P & 479.6 & 496.5 & 425.7 & 495.4 & 359.2 & 440.7 \\
& Exp. & - & - & 400.0 & - & - & - \\
\hline
\end{tabular}

${ }^{a} 2 \mathrm{C}$ refers to the two component relativistic (SO-ZORA/PBE) and $4 \mathrm{C}$ refers to the fourcomponent relativistic (DKS/PBE).

${ }^{b} \mathrm{Pt}(\mathrm{CN})_{2}$ doesn't converge but $\mathrm{Pt}(\mathrm{CN})_{2}{ }^{2-}$ does.

${ }^{c}$ Sar is bond length calculated based on the atomic radii for single bond given by Pekka Pyykkö (the sum of atomic radii for $\mathrm{C}=\mathrm{N}$ double bond is $127 \mathrm{pm}$ ). ${ }^{34}$ ${ }^{d} \omega 1$ is M-C symmetric stretching, $\omega 2$ is $\mathrm{C}-\mathrm{N}$ symmetric stretching, $\omega 3$ is $\mathrm{M}-\mathrm{C}-\mathrm{N}$ bending mode, all calculated using SO-ZORA/PBE. 26 
Table 3: Interaction and bond dissociation energies (in $\mathrm{eV}$ ) together with the multipole derived atomic charges (in a.u.) of $\mathrm{MCN}$ and $\mathrm{M}(\mathrm{CN})_{2}$ molecules $(\mathrm{M}=\mathrm{Pt}, \mathrm{Ds}, \mathrm{Au}, \mathrm{Rg}, \mathrm{Hg}$ and $\mathrm{Cn}$ )

\begin{tabular}{|c|c|c|c|c|c|c|c|}
\hline & \multicolumn{3}{|c|}{ Interaction energy $^{a}$} & \multicolumn{3}{|c|}{ MDC- $\mathrm{q}^{b}$} & \multirow[b]{2}{*}{$\mathrm{BDE}^{c}$} \\
\hline & Pauli & Electrostatic & Total & M & $\mathrm{C}$ & $\mathrm{N}$ & \\
\hline \multicolumn{8}{|c|}{ Monocyanides } \\
\hline $\mathrm{PtCN}^{+}$ & 75.08 & -18.10 & 56.98 & 1.18 & -0.38 & 0.20 & 3.72 \\
\hline DsCN & 82.90 & -20.14 & 62.77 & 0.37 & -0.19 & -0.19 & 3.94 \\
\hline $\mathrm{DsCN}^{-}$ & 82.05 & -20.43 & 61.61 & -0.51 & -0.06 & -0.43 & 2.79 \\
\hline $\mathrm{AuCN}$ & 75.59 & -17.44 & 58.15 & 0.54 & -0.48 & -0.07 & 4.17 \\
\hline $\mathrm{RgCN}$ & 83.59 & -20.49 & 63.09 & 0.39 & -0.32 & -0.07 & 3.57 \\
\hline $\mathrm{HgCN}^{+}$ & 73.08 & -16.10 & 56.98 & 1.23 & -0.38 & 0.15 & 2.51 \\
\hline $\mathrm{CnCN}^{+}$ & 79.80 & -18.98 & 60.81 & 1.08 & -0.29 & 0.21 & 3.08 \\
\hline \multicolumn{8}{|c|}{ Dicyanides $^{d}$} \\
\hline $\mathrm{Pt}(\mathrm{CN})_{2}$ & 146.99 & -32.78 & 114.22 & 0.59 & -0.12 & -0.18 & 3.24 \\
\hline $\mathrm{Ds}(\mathrm{CN})_{2}{ }^{2-}$ & 146.79 & -33.63 & 113.17 & -0.29 & -0.56 & -0.38 & 4.97 \\
\hline $\mathrm{Au}(\mathrm{CN})_{2}{ }^{-}$ & 145.99 & -32.01 & 113.98 & 0.25 & -0.23 & -0.40 & 4.47 \\
\hline $\operatorname{Rg}(\mathrm{CN})_{2}^{-}$ & 156.83 & -35.51 & 121.32 & 0.23 & -0.22 & -0.39 & 4.83 \\
\hline $\mathrm{Hg}(\mathrm{CN})_{2}$ & 148.68 & -32.05 & 116.63 & 0.75 & -0.12 & -0.25 & 4.54 \\
\hline $\mathrm{Cn}(\mathrm{CN})_{2}$ & 156.27 & -34.94 & 121.33 & 0.77 & -0.18 & -0.20 & 4.56 \\
\hline
\end{tabular}

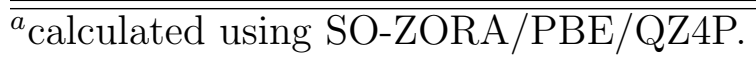

${ }^{b}$ Multipole derived atomic charges (MDC-q) calculated using SO-ZORA/PBE/QZ4P.

${ }^{c}$ Bond dissociation energy (BDE) calculated using mDKS/PBE/dyall-cvtz in ReSpect and is defined for example as $\mathrm{Au}(\mathrm{CN})_{2}^{-} \rightarrow \mathrm{AuCN}+\mathrm{CN}^{-}$. 